\title{
HPV infection and intraepithelial lesions from the anal region: how to diagnose?
}

\begin{abstract}
In the last years, the prevalence of HPV infection in the anal region has increased, especially in some groups like homosexual and HIV-positive people. Since this infection can be associated with the development of squamous anal cancer due to its progression from HPV infection to anal intraepithelial neoplasia (AIN) and finally to cancer, the screening and evaluation of these conditions are important. Anal cytology and high resolution anoscopy are good methods that are available and can be used. Although useful, these methods should be performed correctly and not indiscriminately in all patients. Patients for whom anal cytology screening is recommended are: HIV-infected patients, homosexuals, women who present with high-grade vulvar squamous intraepithelial neoplasia, vulvar cancer or cervical cancer. An abnormal anal cytology should be further evaluated with high resolution anoscopy.
\end{abstract}

Keywords: anal canal; papillomavirus infections; cell biology; carcinoma in situ.

\section{INTRODUCTION}

The association between human papillomavirus (HPV) and squamous anal carcinoma has been strongly demonstrated in the last years. Studies have shown that this association is true in about $93 \%$ of the cases. HPV infection in the anal region, therefore, has a great impact on the development of cancer. Only HPV in the cervix is described to have a greater impact on the development of cancer; actually cervical cancer is close to $100 \%$ associated with HPV. ${ }^{1}$ Studies have show that about 2,000 new cases of HPV-associated anal cancers are diagnosed each year in the United States. ${ }^{2}$

Similarly to what happens in uterine cervix, anal carcinoma is preceded by cellular abnormalities or intraepithelial neoplasias, and these also progress from low-grade lesions to high-grade lesions and finally, depending on some circumstances, to cancer. However, the percentage of regression and progression of the lesions in these patients is unclear., ${ }^{3,4}$ The HPV types implicated in anal intraepithelial neoplasia are similar to those described for the cervix, and it is not infrequent to observe infection by multiple types. ${ }^{5}$

Since the prevalence of anal cancer has been increasing and the precursor conditions can be detected by screening methods, the relevance of using anal cytology and anoscopy as methods to identify these pre-invasive lesions is being questioned. Such questions relate to the groups to be screened and the best way to implement it such screening. The purpose of this study was to review the literature about the use of anal cytology and anoscopy to screening and evaluation of anal intraepithelial neoplasia.

\section{ANAL CYTOLOGY}

Anal cytology is a noninvasive method of screening, which is performed primarily by anal secretion collection through a brush (Dacron swab) introduced into the anal canal and removed with gentle rotation movements. It is indicated to avoid anal sex and douching in the day before the procedure, since these practices can decrease cellular recovery. Special caution should be taken for not touching anal canal warts and rectum walls with the brush to avoid any fecal contamination. It is controversial how deep the swab must be introduced in the anal canal; however, the introduction of $4 \mathrm{~cm}$ from the anal margin seems to be more effective. ${ }^{6}$ The collected material should be smeared on glass microscope slides and immediately fixed with ethanol. Another possibility is the liquid-based cytology by submerging the material obtained in a small glass containing preservative fluid. This method, when available, is preferable
Authors

Newton Sérgio de Carvalho ${ }^{1}$

Aliana Meneses Ferreira ${ }^{2}$ Camila Caroline Tremel Bueno $^{2}$

${ }^{1} \mathrm{PhD}$; Professor of Infectious Diseases, Gynecology and Obstetrics Sector, Department of ObGyn, Hospital de Clínicas, Universidade Federal do Paraná (UFPR), Curitiba, PR, Brazil ${ }^{2}$ Members in Training Infectious Diseases, Gynecology and Obstetrics Sector, Department of ObGyn, Hospital de Clínicas, UFPR, Curitiba, PR, Brazil

Submitted on: 05/01/2011 Approved on: 06/07/2011

Correspondence to: Aliana Meneses Ferreira Rua General Carneiro, 181, Alto da Glória 80060-150, Curitiba, PR, Brazil

ali_ferreira@hotmail.com

We declare no conflict of interest.

(ㅇ)2011 Elsevier Editora Ltda. All rights reserved. 
as it leads lower rates of unsatisfactory slides. ${ }^{7}$ The sample is then processed and analyzed by Papanicolaou methodology and hematoxylin-eosin staining. The appropriate terminology to report the results should be the one suggested by Bethesda criteria, which is shown in Box $1 .^{8}$

Self-collecting of anal cytology samples is an option that can also be used. Apparently, it presents a sensitivity similar to other collection methods. ${ }^{9}$ As more studies confirm this similar efficacy, this kind of collection will probably increase.

Box 1: Description of anal cytology terminology

Unsatisfactory due to inadequate cellularity

Negative for intraepithelial lesion or malignancy

Atypical squamous cells of undetermined significance (ASCUS)

Low-grade squamous intraepithelial lesions (LSIL)

High-grade squamous intraepithelial lesions (HSIL)

There are few studies comparing anal cytology efficacy in detecting intraepithelial lesions with other methods such anoscopy and histology. Nahas et al. ${ }^{10}$ demonstrated that considering histology as the gold-standard anal cytology had a sensitivity of $61 \%$ and $60 \%$ specificity for detecting anal intraepithelial neoplasia (AIN) of any degree. Concerning high-grade AIN, the sensitivity and specificity were, respectively, $16 \%$ and $97 \%$, concluding that anal cytology is not sensitive enough to rule out anal dysplasia and should therefore be complemented by high-resolution anoscopy. Santoso et al. ${ }^{11}$ found a $5.9 \%$ prevalence of cytological changes in women with genital intraepithelial neoplasia, compared to $38 \%$ of women with abnormalities at anoscopy and $12.5 \%$ of biopsy-proven anal intraepithelial neoplasia. These data show a sensitivity and specificity of anal cytology around $8 \%$ and $94 \%$, respectively. This low sensitivity, however, has not been observed in other studies: Fox, ${ }^{12}$ when comparing anal cytology and anoscopy findings, found a sensitivity of $83 \%$ and a specificity of $38 \%$ for anal cytology, indicating that cytology is a useful screening method for highrisk patients. It is believed that the improvement of cytology techniques in the last years contributed to better sensitivity of the method, which in general varies from 50 to $90 \%$. In HIV-infected patients it can reach more than $80 \% .{ }^{13,14}$ Analysis of anal cytology sensitivity in relation to other methods should define what is considered as abnormal anal cytology. Greater sensitivity and lower specificity is observed when features suggestive HPV alone are characterized as abnormal cytology, as opposed to anal intraepithelial neoplasia. ${ }^{15}$

\section{HIGH RESOLUTION ANOSCOPY}

High resolution anoscopy (HRA) is a complementary method that can be used in association with anal cytology for detecting anal abnormalities. This procedure consists in visualizing the anal canal and perianal area by devices that allow image magnification in order to detect colposcopic lesions. It can be performed with a colposcope or a magnifying glass. The colposcope allows a magnificaton of 8 to 20 times, whereas with the magnifying glass it can reach 10 times. Therefore, there is no preference on using one of the other available device. In case the health unit where HIV patients are seen do not have a colposcope, examination with a magnifying glass can be an affordable option. However, the physician experience to exam this region is an paramount importance.

High resolution anoscopy should mainly assess the anal transition zone, in which the columnar epithelium of the rectum and the squamous epithelium of the anal canal are adjacent and where the process of epithelial metaplasia occurs. It is necessary to keep away the anal folds before initiating the anoscopy (Figures 1 and 2).

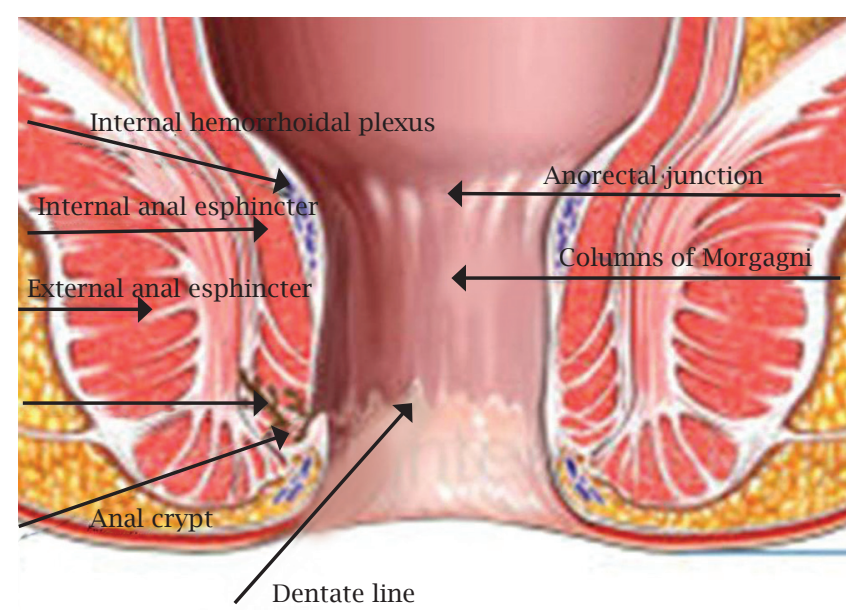

Figure 1: Anal transition zone (Adapted from Medical Images site: http://doctorsgates.blogspot.com).

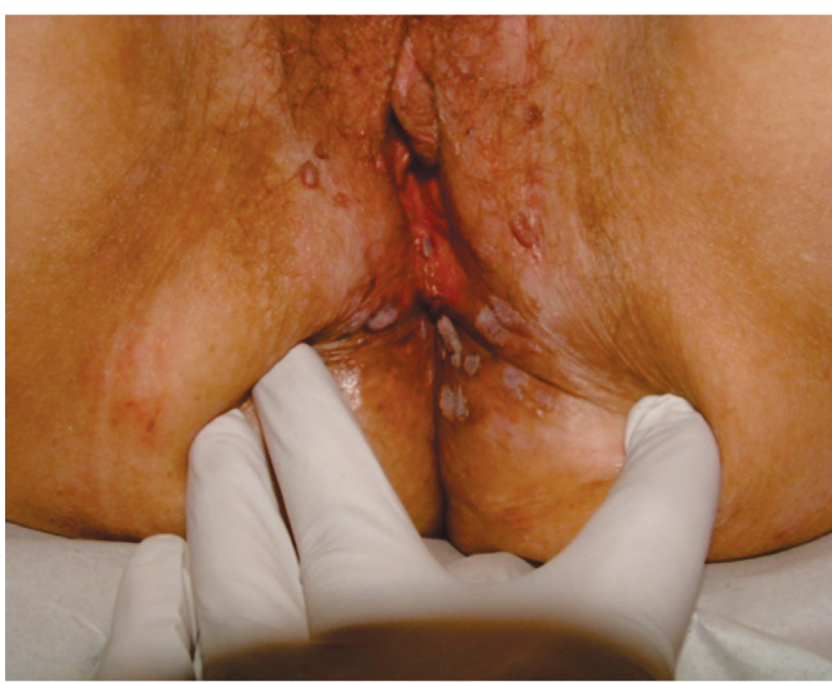

Figure 2: Folds separation before anoscopy. Patient presenting AIN II lesions (collection of Infectious Diseases in Gynecology and Obstetrics Sector Department of ObGyn/ Genital Lesions Ambulatory - DTG/HC-UFPR). 
A gauze pad soaked in 3\% acetic acid and wrapped around a q-tip is inserted in the anal canal prior to visualization and, the acetowhite areas are looked for, similarly to what is observed in cervical colposcopy. ${ }^{5}$ HRA allows the clinician to obtain biopsy specimens of the lesions for histopathologic evaluation. Thereby, hyper-keratotic plaques and pigmented or grayish areas must be biopsied (Figures 3 and 4). ${ }^{9}$ Also, extensive warts as showed in Figure 5 should be biopsied, since a histological definition is needed before management of the lesions.

HRA sensitivity in detecting anal intraepithelial neoplasia among different high-risk populations has been demonstrated to be about 69 to $93 \%$, with a specificity ranging from 32 to $64 \%{ }^{16}$ An important limitation of this method refers to its dependence on the operator's ability to visualize and biopsy the abnormalities. ${ }^{17}$

Some authors consider HRA as a complementary screening test for high-risk patients. ${ }^{10}$ However, there is a tendency to keep HRA as a complementary method to evaluate patients with abnormal anal cytology, since HRA is cheaper and less available than the cytology. Nonetheless, when available, it can also be used as a screening procedure, which increases the sensitivity for identification of anal intraepithelial neoplasia. ${ }^{18}$

\section{RISK FACTORS IMPLICATED IN ANAL INTRAEPITHELIAL NEOPLASIA}

The incidence of anal cancer has increased in some specific groups and not homogenously in the population. Thereby, findings of anal intraepithelial neoplasia tend to be more frequent in these particular groups.

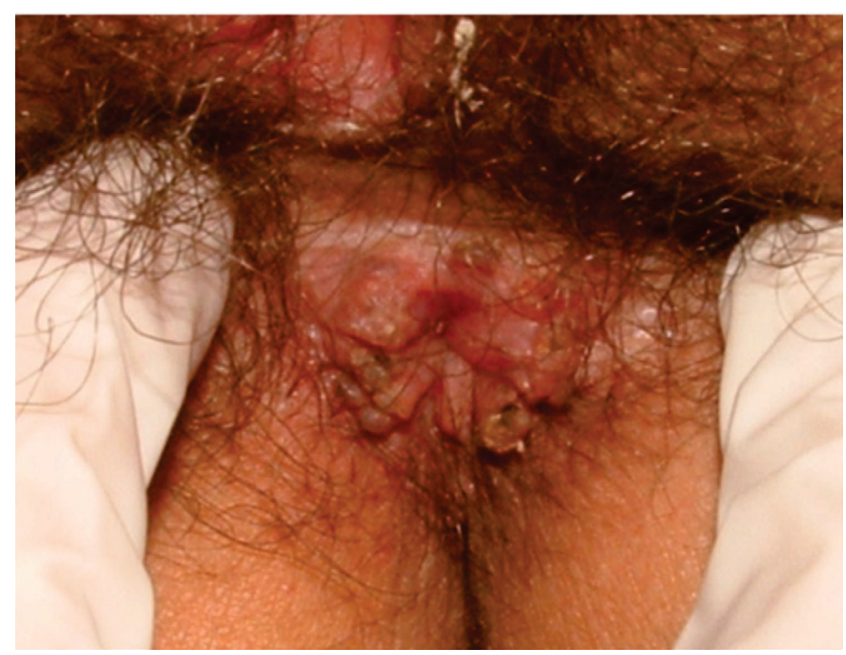

Figure 3: Pigmented area and acetowhite area (collection of Infectious Diseases in Gynecology and Obstetrics Sector Department of ObGyn/Genital Lesions AmbulatoryDTG/HC-UFPR).

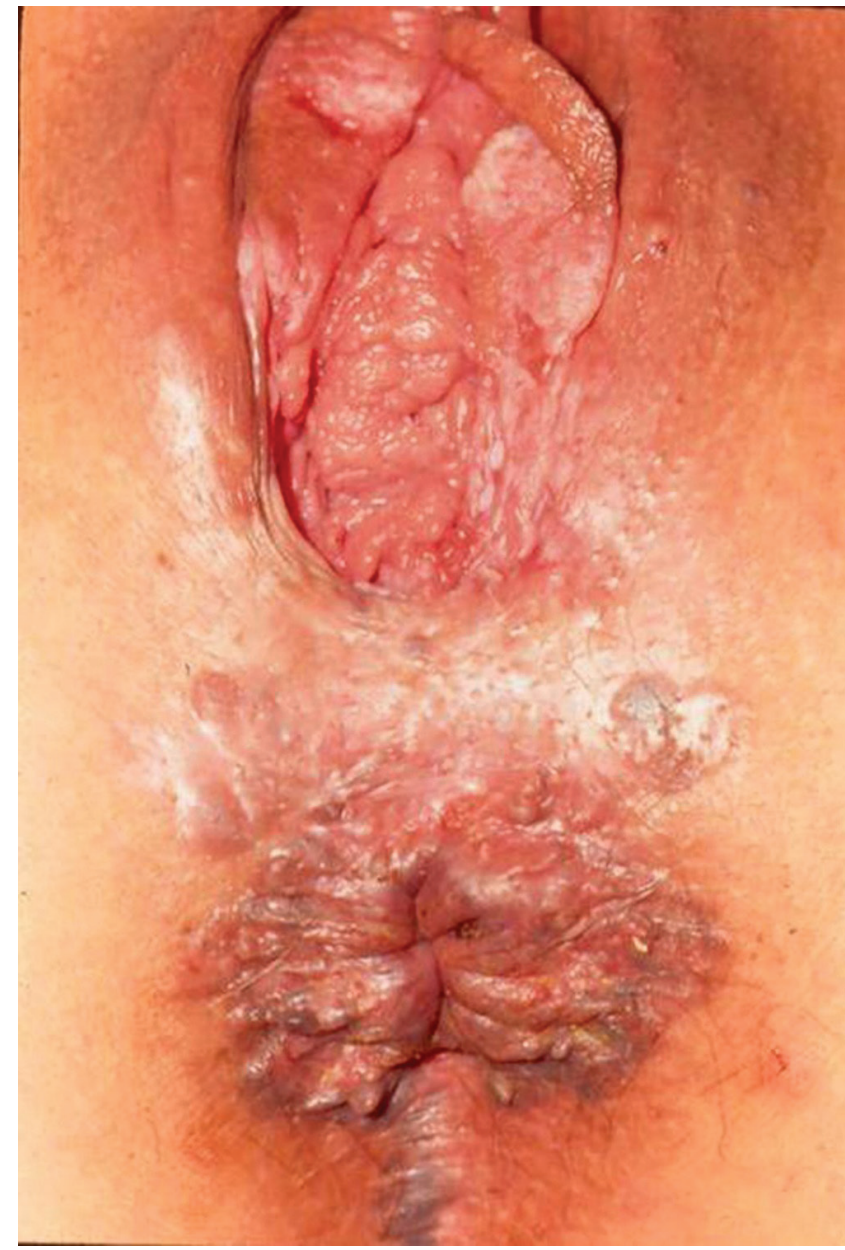

Figure 4: Patient with vulvar intraepithelial neoplasia (VIN) III and anal intraepithelial neoplasia (collection of Infectious Diseases in Gynecology and Obstetrics Sector - Department of ObGyn/Genital Lesions Ambulatory- DTG/HC-UFPR).

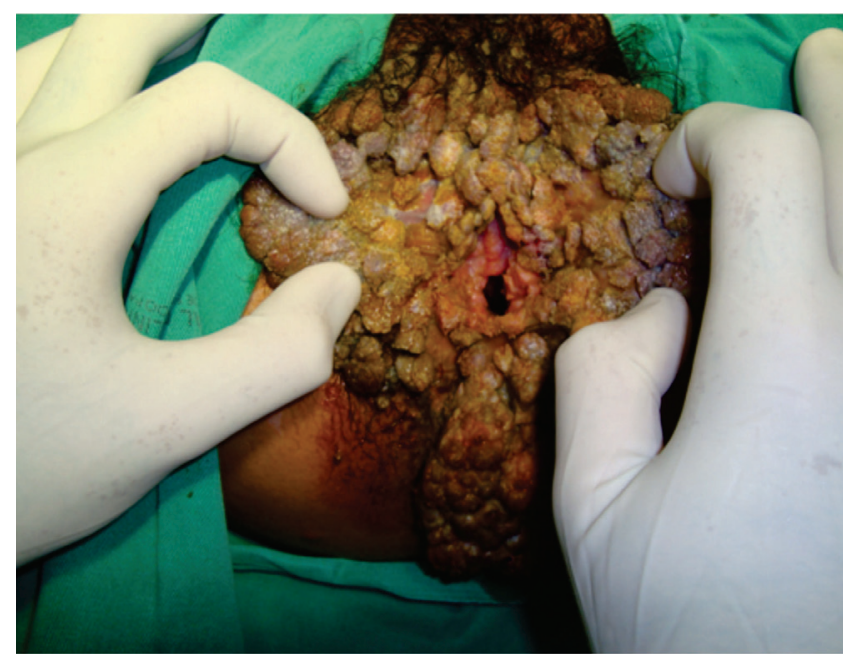

Figure 5: Extensive condylomas in vulvar and perianal regions (collection of Infections Diseases in Gynecology and Obstetrics Sector - Department of ObGyn/Genital Lesions Ambulatory- DTG/HC-UFPR). 
Several studies were conducted in order to identify risk factors for developing anal intraepithelial neoplasia and abnormal anal cytology.

It is well established that HIV-infected patients and men that have sex with men (MSM) who practice anal sex are at higher risk of developing AIN, as well as immunocompromised patients and people with warty lesions above the pectinate line..$^{19,20}$

In the heterosexual female population, however, the issue is more divergent. Anal intercourse has been proposed as an important risk factor in some studies. ${ }^{21,22}$ Nevertheless, Park et al..$^{23}$ did not find a significant association between HPV infection, abnormalities at anal cytology and anal sex practices. As a caveat, this was a small study with 92 women with only nine presenting abnormal anal cytology.

Regarding the association of cervical lesions and anal lesions in women, an important correlation is also suggested. In women presenting cervical intraepithelial neoplasia, the percentage of alterations varies from 9 to $29 \%$. On the other hand, in women with normal cervical cytology, this percentage decreases to less than 5\%. Recently, in spite of the small sample, a study in Brazil showed that among 40 women with cervical lesions, seven presented alterations in anal cytology, in contrast to only one among 40 control women. ${ }^{24}$ Another study demonstrated that of 211 women with cervical intraepithelial neoplasia, abnormal anal cytology were found in $19.5 \%$ of them, in contrast to only $2.5 \%$ in the control group of 80 women. High-grade lesions in the cervix appear to be a risk factor for AIN, as compared to low-grade lesions. ${ }^{10,21,25}$

It is suggested that women with vulvar lesions related to cervical alterations are at a greater risk of presenting abnormal anal cytology, when compared to women with isolated cervical alterations. ${ }^{23}$

HIV-infected women have a higher frequency of abnormal anal cytology in relation to seronegative women, with abnormal cytology in up to $26 \%$ of cases. Hessol et al. ${ }^{26}$ compared $470 \mathrm{HIV}$-infected women to 185 HIV-negative women. Abnormal cytology was found in $21 \%$ of the HIV-infected group compared to $6 \%$ in the control group. This higher frequency of abnormal findings is also related to the concomitant presence of altered cervical cytology and lower levels of CD4 counts. ${ }^{27,28}$

\section{CONCLUSIONS}

Anal cytology is a useful method for screening anal intraepithelial lesions. However, it is indicated only for specific populations who are at high-risk of anal precancerous lesions and, thus, who will likely benefit from this technique.

It is already well-defined that MSM and HIV-infected patients, both men and women, should be screened for anal cytology. Additionally, women who present high- grade vulvar squamous intraepithelial neoplasia, vulvar cancer or cervical cancer must be part of this group, which corresponds to the absolute indications for anal cytology (Box 2).

Some other indications for anal cytology are still controversial. It is not clear about the real need and accuracy of anal cytology in those situations. As part of this group, relative indications for anal cytology could be: women presenting high-grade cervical intraepithelial neoplasia, women with visible lesions in perianal region such as warts, patients that present anal symptomatology (pain, bleeding, itch, irritation, discharge, tenesmus etc.) and women who practice anal sex (Box 3 ).

If any abnormality is found at anal cytology, it is recommended referral to high resolution anoscopy and biopsy of the atypical areas when present. ${ }^{10,12,15} \mathrm{~A}$ new anoscopy six months thereafter is indicated for patients with positive findings. ${ }^{12}$ In cases of initial negative cytology, this procedure should be repeated in order to decrease the possibility of false-negative results.

There is not a guideline concerning routine anal cytology for high-risk patients. Goldie et al. ${ }^{29}$ concluded that annual or biannual anal cytology, regardless of when it is started, is comparable to some preventive measures accepted in public health.

Anal cytology, therefore, consists in a simple and minimally invasive procedure, and it is not difficult to implement as a routine exam in patients at high risk for AIN. In this group of patients, an abnormal anal cytology and complementary evaluation with high resolution anoscopy can effectively diagnose cancer precursor conditions, directing specific treatment, and thus preventing the progression of these lesions, with a significant decrease in morbidity and mortality of the patients.

Box 2: Absolute indications for AIN screening

HIV-infected patients

MSM (men who have sex with men)

Women with high-grade vulvar intraepithelial lesion, vulvar cancer or cervical cancer

Box 3: Relative indications for AIN screening

Women with high-grade cervical intraepithelial lesion Anal symptomatology

Women who practice anal sex

Visible lesions in perianal region 


\section{REFERENCES}

1. Parkin DM. The global health burden of infection-associated cancers in the year 2002. Int J Cancer 2006; 118:3030-44.

2. Joseph DA, Miller JW, Wu X et al. Understanding the burden of human papillomavirus-associated anal cancers in the US. Cancer 2008; 113(S10):2892-900.

3. Jay N, Berry M, Hogeboorn CJ et al. Colposcopic appearance of anal squamous intraepithelial lesions. Dis Col Rectum 1997; 40:919-28.

4. Palefski J, Gonzales J, Greenblatt RM et al. Anal intraepithelial neoplasia and anal papillomavirus infection among homosexual males with group IV HIV disease. JAMA 1990; 263:2911-6.

5. Palefsky JM, Holly EA, Ralston ML et al. Prevalence and risk factors for human papillomavirus infection of the anal canal in immunodeficiency virus HIV-positive and HIV-negative homosexual men. J Infect Dis 1998; 177:361.

6. Nadal SR, Horta SHC, Calore EE et al. How deep must the brush be introduced in the anal canal for a more effective cytological evaluation? Rev Assoc Med Bras 2009; 55(6):749-51.

7. Bean SM, Chhieng DC. Anal-rectal cytology: a review. Diagn Cytopathol 2010; 38(7):538-46.

8. Coutinho JRH. Premalignant screening for anal lesions - anal cytology and high resolutions anoscopy. New resources for prevention. Rev Col Bras Cir 2006; 33(5):311-7..

9. Cranston RD, Darragh TM, Holly EA et al. Anal intraepithelial neoplasia: diagnosis, screening and treatment. J Acquir Immune Defic Syndr 2004; 36(4):915-20.

10. Nahas CS, da Silva Filho EV, Segurado AA et al. Screening anal dysplasia in HIV-infected patients: is there an agreement between anal pap smear and high-resolution anoscopy-guided biopsy? Dis Colon Rectum 2009; 52(11):1854-60.

11. Santoso JT, Long M, Crigger M et al. Anal Intraepithelial neoplasia in women with genital intraepithelial neoplasia. Obstet Gynecol 2010; 116(3):578-82.

12. Fox PA. Human papillomavirus and anal intraepithelial neoplasia. Curr Opin Infect Dis 2006; 19(1):62-6.

13. Parés D, Mullerat J, Pera M. Anal intraepithelial neoplasia. Med Clin (Barc) 2006; 127;749-55.

14. Vajdic CM, Anderson JS, Hillman RJ et al. Blind sampling is superior to anoscope guided sampling for screening for anal intreapithelial neoplasia. Sex Transm Infect 2005; 81:415-8.

15. Ruiter A, Carter P, Katz DR et al. A comparison between cytology and histology to detect anal intraepithelial neoplasia. Genitourin Med 1994; 70(1):22-5.
16. Chiao EY, Giordano TP, Palefsky JM et al. Screening HIV-infected individuals for anal cancer precursor lesions: a systematic review. Clin Infect Dis 2006; 43(2):223-33.

17. Park, IU, Palefsky JM. Evaluation and Management of anal intraepithelial neoplasia in HIV-negative and HIV-positive men who have sex with men. Curr Infect Dis Rep 2010; 12(2):126-33.

18. Fox PA. Anal cancer screening in men who have sex with men. Curr Opin HIV AIDS 2009; 4(1):64-7.

19. Metcalf AM, Dean T. Risk of dysplasia in anal condyloma. Surgery 1995 ; 118:724-6.

20. Palefsky JM, Holly EA, Gonzales J et al. Natural history of anal cytologic abnormalities and papillomavirus infection among homosexual men with group IV HIV disease. J AIDS 1992; 5:1258-65.

21. Moscicki AB, Hills NK, Shiboski S et al. Risk factors for abnormal anal cytology in young heterosexual women. Cancer Epidemiol Biomarkers Prev 1999; 8(2):173-8.

22. Holly EA, Ralston ML, Darragh TM et al. Prevalence and risk factors for anal squamous intraepithelial lesions in women. JNCI J Natl Cancer Inst 2001; 93(11):843-9.

23. Park IU, Ogilvie JW Jr, Anderson KE et al. Anal human papillomavirus infection and abnormal anal cytology in women with genital neoplasia. Gynecol Oncol 2009; 114(3):399-403.

24. Zanine RM, Fabro APW, Gomez DB et al. Prevalence of abnormal anal cytology in women with abnormal Pap smear. Rev Bras Genitoscopia 2009; 3(3-4):76-9.

25. Giraldo P, Jacyntho C, Costa C et al. Prevalence of anal squamous intra-epithelial lesion in women presenting genital squamous intra-epithelial lesion. Eur J Obstet Gynecol Reprod Biol 2009; 142(1):73-5.

26. Hessol NA, Holly EA, Efird JT et al. Anal intraepithelial neoplasia in a multiside study oh HIV-infected and high-riskHIV-uninfected women. AIDS 2009 jan 2;23(1);59-70

27. Tandon R, Baranoski AS, Huang F et al. Abnormal anal cytology in HIV-infected women. Am J Obstet Gynecol 2010; 203(1):21.e1-6.

28. Williams AB, Darragh TM, Vranizan K et al. Anal and cervical human papillomavirus infection and risk of anal and cervical epithelial abnormalities in human immunodeficiency virusinfected women. Obstet Gynecol 1994; 83(2):205-11.

29. Goldie SJ, Kuntz KM, Weinstein MC et al. The clinical effectiveness and costeffectiveness of screening for anal squamous intraepithelial lesions in homosexual and bisexual HIV-positive men. JAMA1999; 281(19):1822-9. 